\title{
Simulation of Water Level Control in a Tank Using Fuzzy Logic
}

\author{
${ }^{1}$ Disha ${ }^{2}$ Mr. Pawan Kumar Pandey ${ }^{3}$ Rajeev Chugh \\ ${ }^{1}$ Research Scholar ${ }^{2}$ Asst. Prof. EEE Deptt. ${ }^{3}$ Research Scholar \\ ${ }^{1,2,3}$ BRCMCET, Bahal, Bhiwani, Haryana, India-127028.
}

\begin{abstract}
In control systems there are a number of generic systems and methods which are encountered in all areas of industry and technology. From the dozens of ways to control any system, it turns out that fuzzy is often the very best way. The only reasons are faster and cheaper. One of successful application that used fuzzy control is water tank level control. The purpose of this project is to design a simulation system of fuzzy logic controller for water tank level control by using simulation package which is Fuzzy Logic Toolbox and Simulink in MATLAB software. In order to find the best design to stabilize the water level in the system, some factors will be considered. For this project, the water level was controlled by using three rules of membership function which then extended to five rules and seven rules for verification purpose and further improvement of the system. Besides that, several of different methods also been used in order to design the most stabilize system and this project was focused to the software part only. By doing some modification of this project, the design will be very useful for the system relates to liquid level control that widely use in industry nowadays.
\end{abstract}

\section{Introduction}

Combined water tank systems are used in many resident areas. Most of the time they are functioning well, but there are some condition that the system faces the problem of overflows because of the system cannot detect whether the water level have properly reach the desired level or the flow-in rate of the water are not proportional with the flow-out rate. It can cause the water tank system empties faster than it fills up. Consequently, the pressure of the water cannot support the distribution of the water to the resident area.

Construction of new tank, valve or system could be the solution to completely eliminate the problems. However, such schemes are expensive and can also be extremely disruptive because the system networks may extend across wide geographical areas. Alternatively, controlling the flow between parts of the system which are under different loading can reduce the overflow spills. Actuated valve can be opened or closed to control the flow past a certain point. The implementation of the Fuzzy Logic Controller in water tank level control system can be used to overcome this problem. By doing some modification of this project, the problem can be solved in the simplest and cheapest possible controller for a given application. The basic idea is still the same and the modification will be made depends on the design expectation. One interesting features of this water tank system is that the tank empties much more slowly than it fills up because of the specific value of the outflow diameter pipe. It can deal with this by setting of the valve membership function. Although this project only focusing on software simulation not really on the hardware, but this is the best step that should be considered before any implementation of the system be constructed. By testing the system in this simulation area, the expected output from the input can be set earlier based on the rules set. The uses of MATLAB card is most required in order integrating the software and hardware parts of the system and the cost of MATLAB card is quite high. Besides that, the hardware implementation of the simulated design is also requires a longer time. Those are the reasons why this project will be concentrate on the software simulation part only.

\section{Defining the structure}

As discussed in the previous chapter, in FIS editor first of all the structure of the system is defined. Here in the structure shown below there are 3 inputs and 3 outputs. The 3 inputs are:

1. Level

2. Rate

3. Pressure

The 3 outputs are:

1. Valve

2. Fire

\section{Steam valve}

The middle block contains the rules which are formed using different combinations of the inputs used.

One in all it can be said that the FIS editor displays the information about the fuzzy inference system 


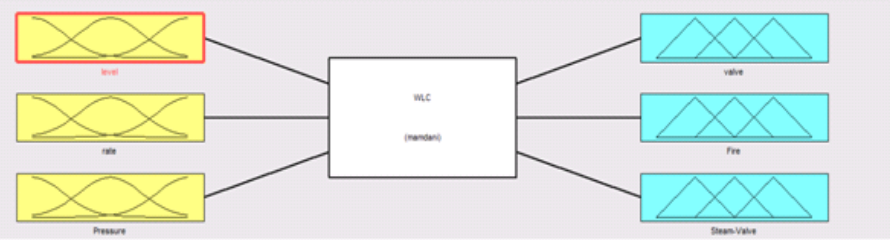

Fig.1 FIS editor displaying the overall structure

1. Defining the membership function and membership degree for all the input and output variables After defining the structure in FIS editor the GUI tool that come into play is membership editor.

As discussed in previous chapter we can choose any type of membership function among the various types like trapMF, triMF, GuassMF etc. For the first input variable i.e 'Level' in this project the type of membership function used is guassMF. Also we can use any number of membership degrees for the membership function of a variable. There are 3 membership degrees have been used for the first input variable. They are:
1. Negative
2. Moderate
3. Positive

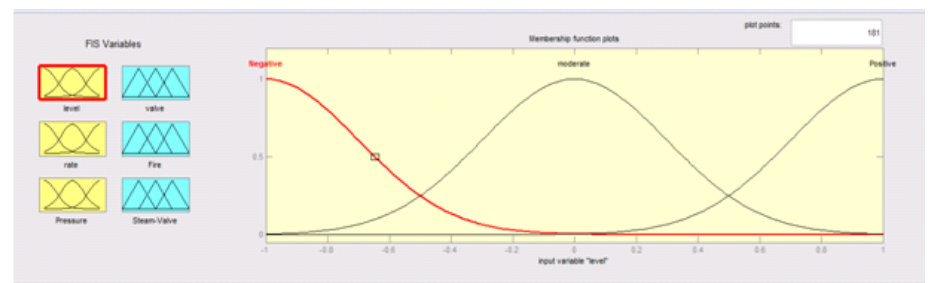

Fig.2 Membership editing of the first input variable

For the second input variable i.e 'Rate' in this project the type of membership function used is guassMF. There are 3 membership degrees have been used for the second input variable. They are:

1. Negative

2. Zero

3. Positive

Similarly here also the range of the membership degree can be varied according to the requirement.

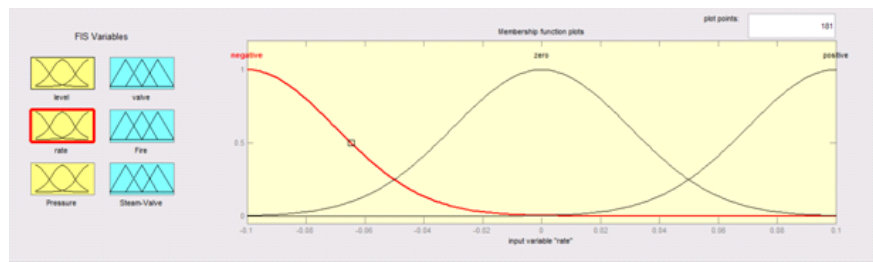

Fig.3 Membership editing for the second input variable

For the third input variable i.e 'pressure' in this project the type of membership function used is triMF. There are 3 membership degrees have been used for the third input variable. They are:

1. Zero

2. Small

3. Large

Similarly here also the range of the membership degree can be varied according to the requirement.

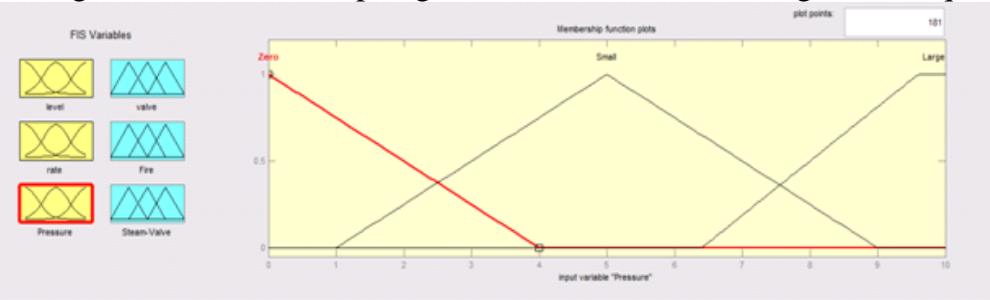

Fig.4 Membership editing for the third input variable

For the first output variable i.e 'Valve' in this project the type of membership function used is triMF. There are 5 membership degrees have been used for the first output variable. They are:

1. Fast Closing 
2. Slow Closing

3. Unchanged

4. Slow opening

5. Fast opening

Similarly here also the range of the membership degree can be varied according to the requirement.

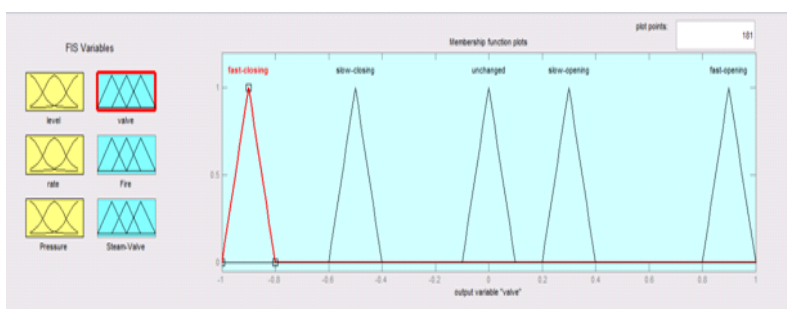

Fig.5 Membership editing for the first output variable

For the second output variable i.e 'Fire in this project the type of membership function used is triMF. There are 2 membership degrees have been used for the output variable. They are:

1. OFF

2. ON

Similarly here also the range of the membership degree can be varied according to the requirement.

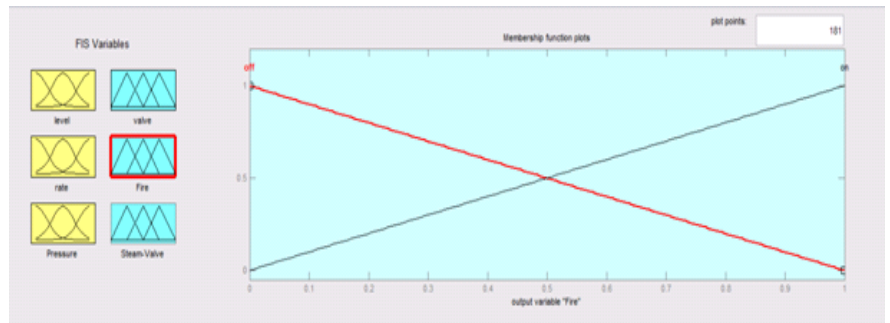

Fig.6 Membership editing for the second output variable

For the third output variable i.e 'Steam Valve' in this project the type of membership function used is triMF. There are 2 membership degrees have been used for the output variable. They are:

1. Closed

2. Open

Similarly here also the range of the membership degree can be varied according to the requirement.

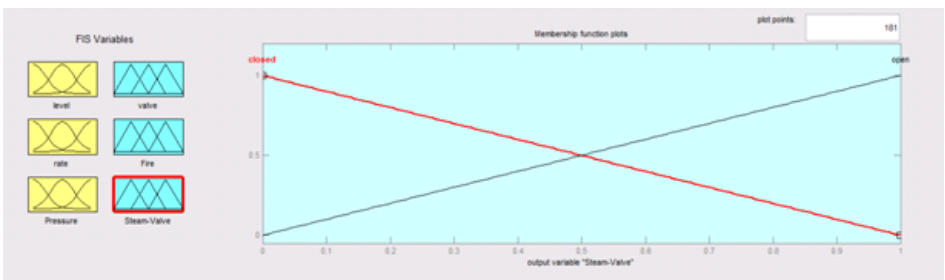

Fig.7 Membership editing for the third output variable

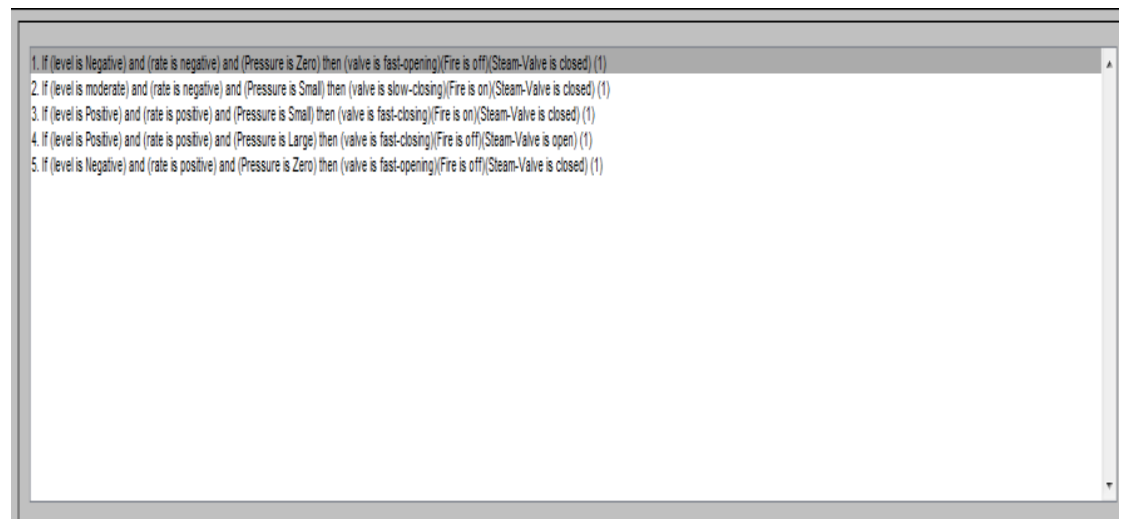

Fig.8 Rule editor 


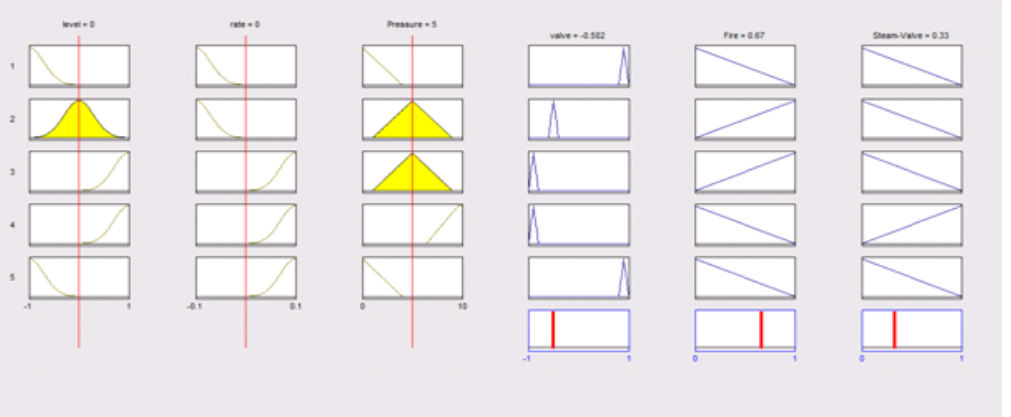

Fig.9 Rule viewer

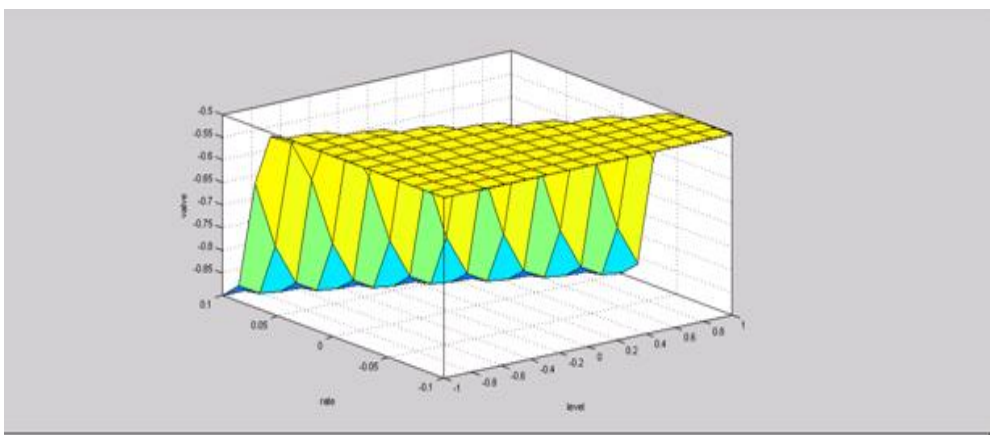

Fig.10 Surface viewer

\section{Conclusion}

It can be easily concluded by analyzing the outputs of fuzzy and PID controller that the controlled output signal through fuzzy controller remains always stable without any tuning but in PID controller the parameters are required to be tuned over a period of time to get the stabilized output due to occurrence of nonlinearities in the system.

\section{References}

[1] Fuzzy PID Supervision for a Nonlinear, System: Design and Implementation Multimedia Communications (Mediacom), 2010 International Conference on, Date of Conference: 7-8 Aug. 2010 Author(s): Qianhua Xiao Dept. of Inf. Eng., Nanchang Univ., Nanchang, China Deqiong Zou ; Ping Wei

[2] Fuzzy PID Supervision for a Nonlinear, System: Design and Implementation Fuzzy Information Processing Society, 2007. NAFIPS '07. Annual Meeting of the North American Date of Conference: 24-27 June 2007 Author(s): Sehab, R. Pare Univ. Laval-Change, Laval

[3] Parallel distributed compensator design for process control based on fuzzy Takagi-Sugeno model Power Engineering and Automation Conference (PEAM), 2011 IEEE Date of Conference: 8-9 Sept. 2011 Author(s): Sadeghi, M.S. Control \& Power Eng. Dept., Shiraz Univ. of Technol., Shiraz, Iran Farughian, A.

[4] Swarm Intelligence Based Fuzzy Controller -- A Design for Nonlinear Water Level Tank Intelligent Systems, Modelling and Simulation (ISMS), 2012 Third International Conference on Date of Conference: 8-10 Feb. 2012 Author(s): Joshani, M. Dept. of Robot. \& Autom. Control, Univ. of Technol. of Malaysia, Malaysia Khalid, M. ; Yusof, R. ; Cahyadi, A.I.

[5] Development and application of a gradient descent method in adaptive model reference fuzzy control. TENCON 2000. Proceedings Date of Conference: 2000 Author(s): Naman, A.T. Electr. Eng. Dept., Univ. Malaya Abdulmuin, M.Z. ; Arof, H.

[6] Level Control in Horizontal Tank by Fuzzy Logic Controller SICE-ICASE, 2006. International Joint Conference Date of Conference: 18-21 Oct. 2006 Author(s): Tunyasrirut, S. Dept. of Instrum. Eng., Pathumwan Inst. Of Technol., Bangkok Wangnipparnto, $\mathrm{S}$.

[7] L.A. Zadeh. Fuzzy

[8] Babu ska, R., H.A.B. te Braake, A.J. Krijgsman and H.B. Verbruggen (1996). Comparison of intelligent control schemes for realtime pressure control. Control Engineering Practice 4(11), 1585-1592.

[9] Babu`ska, R., H.J.L. van Can and H.B. Verbruggen (1996). Fuzzy modeling of enzymatic Penicillin-G conversion. In Preprints 13th IFACWorld Congress, Volume N, San Francisco,USA, pp. 479-484.

[10] Babu ska, R. and H.B. Verbruggen (1995). Identification of composite linear models via fuzzy clustering. In Proceedings European Control Conference, Rome, Italy, pp. 1207-1212.Bezdek, J.C. (1981). Pattern Recognition with Fuzzy Objective Function. Plenum Press, NewYork.

[11] Brown, M. and C. Harris (1994). Neurofuzzy Adaptive Modelling and Control. New York:Prentice Hall. Buchanan, B.G. and E.H. Shortliffe (1984). Rule-Based Expert Systems. Readings (MA), USA:Addison-Wesley.Driankov, D., H. Hellendoorn and M. Reinfrank (1993). An Introduction to Fuzzy Control.Springer, Berlin.

[12] Fuzzy sets and systems: theory and applications, Volume 144of Mathematics in science and engineering. Academic Press.Filev, D.P. (1996). Model based fuzzy control. In Proceedings Fourth European Congress on Intelligent Techniques and Soft Computing EUFIT'96, Aachen, Germany.Friedman, J.H. (1991). Multivariate adaptive regression splines. The Annals of Statistics 19(1), 1141.

[13] Gustafson, D.E. and W.C. Kessel (1979). Fuzzy clustering with a fuzzy covariance matrix. In Proc. IEEE CDC, San Diego, CA, USA, pp. 761-766.Hartog, den, M.H., R. Babu ska, H.J.R. Deketh, M. Alvarez Grima, P.N.W. Verhoef and H.B. 